\title{
ПЕРСПЕКТИВЫ СЕЛЕКЦИИ СМОРОДИНЫ ЧЕРНОЙ ПО КАЧЕСТВУ ЯГОД В УСЛОВИЯХ БАШКИРСКОГО ПРЕДУРАЛЬЯ
}

\section{R.A. Nigmatzyanov, V.N. Sorokopudov \\ THE PROSPECTS OF BLACK CURRANT SELECTION FOR BERRIES' FRUIT QUALITY UNDER THE CONDITIONS OF THE BASHKIR CIS-URALS}

\begin{abstract}
Нигматзянов Радмил Асхатович - науч. сотр. Кушнаренковского селекционного центра по плодово-ягодным культурам и винограду Башкирского НИИ сельского хозяйства УФИЦ PAН, Республика Башкортостан, Кушнаренковский р-н, с. Кушнаренково.

E-mail: sorokopud2301@mail.ru
\end{abstract}

Сорокопудов Владимир Николаевич - д-р с.-х. наук, проф., зав. центром генетики, селекции и интродукции садовых культур Всероссийского селекционно-технологического института садоводства и питомниководства, г. Москва.

E-mail: sorokopud2301@mail.ru

Цель исследования - создание и выделение доноров высокого содержания биологически активных веществ в ягодах смородины черной. Объектами исследований послужили сорта и отборные формы смородины черной селекции Башкирского НИИСХ. В качестве контроля послужил сорт Валовая. Повторность опыта трехкратная, в каждой повторности по 10 растений по схеме посадки $3 \times 1$ м. Биохимические анализы ягод проводились по общепринятым методикам. В период 20132017 ге. биохимический состав был изучен у 8 сортов и 20 отборных форм смородины черной местной селекции. В ягодах смородины черной сумма сахаров по среднему значению по всем изучаемым сортообразцам варьировала om 7,8 \% у сорта Валовая и до 10,4 \% у сортообразиа 3-49. У контрольного сорта Валовая он был равен 7,8 \% и практически все сорта и формы превосходили контрольный сорт по содержанию сахаров в ягодах. Выделились образцы с самым высоким содержанием сахаров А-1, А-2, А-3, 3-49, 3-45, 5-11 и сорт Бельская, у которых содержание сахаров превышало $10 \%$. За период исследования по содержанию витами-
Nigmatzyanov Radmil Askhatovich - Staff Scientist, Kushnarenkovsky Selection Center for Fruit and Berry Cultures and Grapes, Bashkir Research and Development Institute of Agriculture UFRC RAS, the Republic of Bashkortostan, Kushnarenkovsky District, V. Kushnarenkovo.

E-mail: sorokopud2301@mail.ru

Sorokopudov Vladimir Nikolaevich - Dr. Agr. Sci., Prof., Head, Center of Genetics, Selection and Introduction of Garden Cultures, All-Russian Selection Institute of Technology of Gardening and Nursery, Moscow.

E-mail: sorokopud2301@mail.ru

на C по сортообразиам варьирование составило om 152 мг/\% copm Валовая до 205,3 мг/\% у сорта Иремель. Среди сортообразцов значительная часть имела содержание витамина $C$ om 150 мг/100 г и выше. В некоторых сортах Чишма и Иремель и образцах 3-45, 3-49 и A-1 содержание составило более 200,0 м2/100 2. В результате проведенного исследования генофонда смородины черной Башкирского НИИСХ по биохимическому составу ягод установлено: 1) в качестве источников высокого содержания аскорбиновой кислоты выделены сорта Чишма и Иремель и сортообразцы 3-45, 3-49 и A-1 с высокими стабильными показателями по годам выше 200 мг\%; 2) среди сортов источниками повышенного содержания сахаров свыше $10 \%$ рекомендуется Бельская и сортообразцы А-1, А-2, А-3, 3-49, 3-45, 5-11; 3) в качестве комплексных источников повышенного содержания в ягодах аскорбиновой кислоты и сахаров выделены сорта Чишма и Иремель и перспективные формы А-1, 3-49, 3-55, 5-11.

Ключевые слова: смородина черная, сорт, источник признака, аскорбиновая кислота, сахара. 
The research objective was the creation and allocation of donors of high content of biologically active agents in blackcurrant berries. As the objects of the researches the varieties and perfect forms of currant of black selection of the Bashkir RDIA were used. The variety Valovaya served as the control. The frequency of the experiment was triple, in each frequency on 10 plants according to the scheme of planting $3 \times 1 \mathrm{~m}$. Biochemical analyses of berries were carried out by the standard techniques. During 2013-2017 biochemical structure was studied in 8 varieties and 20 perfect forms of currant of black local selection. In blackcurrant berries the sum of sugars on average value on all studied variety specimens was from $7.8 \%$ in the variety Valovaya and to $10.4 \%$ in specimen 3-49. At the control variety Valovaya it was equal to $7.8 \%$ and practically all the varieties and forms surpassed the control variety in the content of sugars in berries. The samples with the highest content of A-1, A-2, A-3,3-49, 3-45, 5-11 sugars and the variety Belskaya which content of sugars exceeded $10 \%$ were allocated. During the research on the content of vitamin $C$ on the specimen the variation made from $152 \mathrm{mg} / \%$ variety Valovaya to $205.3 \mathrm{mg} / \%$ in the variety Iremel. Among the specimen considerable part had the content of vitamin C from $150 \mathrm{mg} / 100$ and above. In some varieties Chishma and Iremel and samples 3-45, 3-49 and A-1 the contents made more than $200.0 \mathrm{mg} / 100$. As the result of conducted research of a gene pool of blackcurrant of the Bashkir RDIA on biochemical structure of berries it was established: 1) as the sources of high content of ascorbic acid the varieties Chishma and Iremel and the varietals 3-45, 3-49 and A-1 with high stable rates by years higher than $200 \mathrm{mg}$ of \% were allocated; 2) among the varieties over $10 \%$ were marked by the sources of raised sugar content Belskaya and the varietals of $A-1, A-2, A-3,3-49,3-45,5-11 ; 3)$ as complex sources of raised contents of ascorbic acid and sugars in berries the varieties Chishma and Iremel and perspective A-1, 3-49, 3-55, 5-11 forms were allocated.

Keywords: black currant, variety, the source of sign, ascorbic acid, sugars.

Введение. Род Смородина (Ribes L.) принадлежит к семейству Grossulariaceae и включает по разным данным от 120 до 150 видов [1-3], которые разделяют на восемь подродов. Самый распространенный в культуре и широко известный вид смородины - смородина черная (Ribes nigrum L.) [4-5].
По данным исследователей, по химическому составу ягод смородины черной содержание сухих растворимых веществ в некоторые годы у отдельных сортов достигала 18-20\% [6-10], в то время как у других сортов может составлять 12,2$12,5 \%$. Сахара представлены в основном глюкозой, фруктозой и сахарозой и определяют пищевую ценность плодов.

Смородина черная имеет широкое распространение в Республике Башкортостан, но урожайность ее продолжает оставаться низкой, особенно в производственных условиях. В повышении урожайности насаждений этой культуры большое значение отводится сорту, приспособленному к суровым местным условиям. К новым сортам предъявляются следующие требования: урожай более 10,0 т/га, самоплодность не менее $30 \%$, устойчивость к основным болезням (мучнистая роса, антракноз, махровость), хорошее качество ягод (масса более 1 г) разного срока созревания, приподнятая форма куста.

Селекционная работа по черной смородине была начата в начале 30-х годов прошлого столетия на бывшей Башкирской плодово-ягодной опытной станции. Она заключалась в сборе и размножении наиболее интересных фрорм дикорастущей смородины, в основном представленных европейской разновидностью. Так были выявлены формы, названные Башкирская Черная, Башкирская Урожайная, Горная, которые составили основу районированного сортимента того времени. Следующим этапом была аналитическая селекция, высевались семена от свободного опыления сортов европейского подвида: Неаполитанская, Боскопский Великан, Голиаф, Лия Плодородная, Русская Крупноплодная, а также форм, отобранных из дикорастущей смородины.

В настоящее время основным методом выведения новых сортов смородины черной остается отдаленная межвидовая гибридизация с привлечением вида дикуша и форм сибирского и европейского подвидов. Этим методом созданы сорта Башкирского НИИСХ, выведенные в соавторстве с ФГБНУ ВСТИСП: Бобровая, Валовая, Баррикадная, - включенные в Государственный реестр селекционных достижений. В Госреестр включены сорта Караидель (2001) и Чишма (2013) селекции Башкирского НИИСХ. Проходят государственное сортоиспытание сорта Эстафета (2013), Бельская и Труженица с 2016 года, Иремель - с 2018 года. 
Создание сортов, адаптированных к местным климатическим условиям, продуктивных, с хорошим качеством ягод - одна из основных задач селекции Башкирского НИИСХ.

Цель исследования: создание и выделение доноров высокого содержания биологически активных веществ в ягодах смородины черной.

Объекты и методика исследования. Объектами исследования послужили сорта и отборные формы смородины черной селекции Башкирского НИИСХ. В качестве контроля послужил сорт Валовая. Повторность опыта трехкратная, в каждой повторности по 10 растений по схеме посадки $3 \times 1$ м. Биохимические анализы ягод проводились по общепринятым методикам [11-14].
Результаты исследования и их обсуждение. За период 2013-2017 гг. биохимический состав был изучен у 8 сортов и 20 отборных форм смородины черной местной селекции. В ягодах смородины черной сумма сахаров по среднему значению по всем изучаемым сортообразцам варьировала от 7,8 \% у сорта Валовая и до 10,4 \% у сортообразца 3-49 (табл. 1). У контрольного сорта Валовая он был равен 7,8 \%, и практически все сорта и формы превосходили контрольный сорт по содержанию сахаров в ягодах. Выделились образцы с самым высоким содержанием сахаров: А-1, A-2, A-3, 3-49, 3-45, 5-11 и сорт Бельская, - у которых содержание сахаров превышало $10 \%$.

Таблица 1

\section{Содержание сахаров в ягодах смородины черной}

\begin{tabular}{|l|c|c|c|c|c|c|}
\hline \multirow{2}{*}{ Сортообразец } & \multicolumn{5}{|c|}{ Общий сахар, \% по годам } & \multirow{2}{*}{ Среднее } \\
\cline { 2 - 6 } Валовая & 2013 & 2014 & 2015 & 2016 & 2017 & \\
\hline Чишма & 7,0 & 7,5 & 7,6 & 7,9 & 8,9 & 7,8 \\
\hline Караидель & 8,5 & 9,3 & 9,4 & 7,2 & 8,8 & 8,6 \\
\hline Кушнаренковская & 9,5 & 8,8 & 9,6 & 6,3 & 8,3 & 8,5 \\
\hline Бельская & 8,6 & 8,7 & 9,7 & 7,6 & 8,1 & 8,5 \\
\hline Эстафета & 10,3 & 10,3 & 10,2 & 10,3 & 10,4 & 10,3 \\
\hline Иремель & 9,5 & 9,0 & 9,3 & 9,3 & 9,0 & 9,2 \\
\hline Труженица & 9,6 & 8,8 & 9,3 & 9,8 & 9,2 & 9,3 \\
\hline № 5-21 & 9,5 & 9,8 & 9,9 & 9,6 & 9,9 & 9,7 \\
\hline № 3-26 & 10,2 & 9,9 & 10,0 & 8,3 & 7,8 & 9,1 \\
\hline № 1-9-88 & 10,4 & 9,9 & 10,1 & 9,9 & 8,0 & 9,7 \\
\hline № 5-10 & 10,2 & 9,8 & 9,9 & 8,3 & 7,8 & 9,1 \\
\hline № 5-11 & 10,2 & 10,1 & 9,9 & 9,9 & 8,7 & 9,7 \\
\hline № 3-56 & 10,3 & 10,2 & 9,8 & 9,7 & 9,8 & 10,0 \\
\hline № 4-16 & 9,9 & 9,8 & 8,9 & 8,6 & 8,8 & 9,9 \\
\hline № 1-9-76 & 9,6 & 9,9 & 10,1 & 8,5 & 9,7 & 9,6 \\
\hline № 1-9-79 & 9,8 & 9,6 & 9,8 & 9,7 & 9,6 & 9,7 \\
\hline № 1-9-66 & 9,6 & 10,2 & 9,9 & 9,9 & 9,7 & 9,8 \\
\hline № 3-55 & 9,2 & 9,8 & 9,5 & 9,8 & 9,6 & 9,6 \\
\hline № 3-49 & 10,0 & 9,8 & 10,3 & 10,2 & 10,1 & 10,0 \\
\hline № 1-9-92 & 10,2 & 10,5 & 10,4 & 10,4 & 10,3 & 10,4 \\
\hline № 1-6-82 & 9,9 & 9,9 & 9,6 & 8,7 & 8,7 & 9,4 \\
\hline № 1-5-84 & 9,9 & 9,6 & 9,8 & 9,3 & 9,0 & 9,5 \\
\hline № A-1 & 9,2 & 9,9 & 8,8 & 9,9 & 9,7 & 9,5 \\
\hline № A-2 & 10,6 & 10,0 & 10,2 & 10,3 & 10,2 & 10,3 \\
\hline № A-3 & 9,9 & 9,8 & 10,3 & 10,2 & 10,1 & 10,0 \\
\hline № 10-243 & 10,3 & 9,9 & 9,8 & 10,0 & 9,9 & 10,0 \\
\hline № 10-253 & 8,3 & 8,8 & 8,6 & 8,7 & 8,8 & 8,6 \\
\hline
\end{tabular}


За период исследования по содержанию витамина C (аскорбиновой кислоты) по сортообразцам варьирование составило от 152 мг/\% у сорта Валовая до 205,3 мг/\% у сорта Иремель (табл. 2).

Среди сортообразцов значительная часть имела содержание витамина С от 150 мг/100 г и выше. В некоторых сортах (Чишма и Иремель) и образцах 3-45, 3-49 и А-1 содержание составило более 200,0 мг/100 г. Анализ сортообразцов на комплексно высокое содержание аскорбиновой кислоты и сахаров в ягодах позволил выделить сорта Чишма и Иремель и формы А-1, 3-49, 3-55, 5-11.

Таблица 2

\section{Содержание аскорбиновой кислоты в ягодах смородины черной}

\begin{tabular}{|l|c|c|c|c|c|c|}
\hline \multirow{2}{*}{ Сортообразец } & \multicolumn{5}{|c|}{ Содержание витамина С, мг/100 г } & \multirow{2}{*}{ Среднее } \\
\cline { 2 - 5 } & 2013 & 2014 & 2015 & 2016 & 2017 & \\
\hline Валовая & 197,0 & 156,3 & 129,3 & 107,1 & 169,8 & 152,0 \\
\hline Чишма & 212,0 & 206,6 & 204,6 & 198,8 & 197,8 & 204,0 \\
\hline Караидель & 192,3 & 173,4 & 119,0 & 122,3 & 193,2 & 160,0 \\
\hline Кушнаренковская & 184,3 & 145,3 & 118,0 & 107,3 & 190,1 & 149,0 \\
\hline Бельская & 164,3 & 166,4 & 168,9 & 98,2 & 190,0 & 157,6 \\
\hline Эстафета & 198,0 & 190,9 & 193,8 & 190,0 & 161,4 & 186,0 \\
\hline Иремель & 218,3 & 223,5 & 223,3 & 160,0 & 201,3 & 205,3 \\
\hline Труженица & 189,3 & 180,5 & 124,0 & 192,3 & 186,3 & 162,5 \\
\hline № 5-21 & 203,0 & 201,5 & 206,0 & 160,0 & 178,5 & 190,0 \\
\hline № 3-26 & 200,3 & 201,2 & 200,7 & 156,0 & 181,8 & 188,0 \\
\hline № 1-9-88 & 188,5 & 179,8 & 165,5 & 83,14 & 169,6 & 157,3 \\
\hline № 5-10 & 200,3 & 200,8 & 200,6 & 156,0 & 196,2 & 190,8 \\
\hline № 5-11 & 198,4 & 196,5 & 201,0 & 198,3 & 196,3 & 198,1 \\
\hline № 3-56 & 178,2 & 167,5 & 130,2 & 144,1 & 180,4 & 160,0 \\
\hline № 4-16 & 180,0 & 133,0 & 118,8 & 116,9 & 185,3 & 146,7 \\
\hline № 1-9-76 & 192,6 & 193,8 & 190,0 & 198,2 & 203,0 & 195,5 \\
\hline № 1-9-79 & 193,6 & 199,6 & 193,5 & 197,8 & 198,7 & 196,6 \\
\hline № 1-9-66 & 196,3 & 197,3 & 195,3 & 197,3 & 197,8 & 196,8 \\
\hline № 3-55 & 199,5 & 198,1 & 200,1 & 203,1 & 201,1 & 200,4 \\
\hline № 3-49 & 205,3 & 200,0 & 201,0 & 203,1 & 204,1 & 202,7 \\
\hline № 1-9-92 & 193,6 & 193,5 & 195,3 & 198,7 & 200,5 & 196,3 \\
\hline № 1-6-82 & 190,3 & 188,6 & 183,6 & 193,4 & 200,0 & 191,2 \\
\hline № 1-5-84 & 190,0 & 185,3 & 186,6 & 189,7 & 203,0 & 191,0 \\
\hline № A-1 & 200,0 & 201,0 & 202,3 & 199,2 & 203,4 & 201,2 \\
\hline № A-2 & 187,3 & 162,8 & 150,2 & 160,3 & 188,6 & 170,0 \\
\hline № A-3 & 188,6 & 153,6 & 153,6 & 161,2 & 187,3 & 168,8 \\
\hline № 10-243 190,0 & 150,2 & 132,3 & 146,3 & 178,9 & 160,0 \\
\hline № 10-253 & 176,2 & 135,2 & 130,1 & 110,0 & 178,9 & 160,0 \\
\hline
\end{tabular}

Выводы. В результате проведенного исследования генофонда смородины черной Башкирского НИИСХ по биохимическому составу ягод установлено:

1. В качестве источников высокого содержания аскорбиновой кислоты выделены сорта Чишма и Иремель и сортообразцы 3-45, 3-49 и
A-1 с высокими стабильными показателями по годам выше 200 мг\%.

2. Среди сортов источниками повышенного содержания сахаров свыше $10 \%$ рекомендуется Бельская и сортообразцы А-1, А-2, А-3, 3-49, 3-45, 5-11. 
3. В качестве комплексных источников повышенного содержания в ягодах аскорбиновой кислоты и сахаров выделены сорта Чишма и Иремель и перспективные формы А-1, 3-49, 3-55, 5-11.

\section{Литература}

1. Цвелев Н.Н. Семейство Крыжовниковые (Grossulariaceae) // Жизнь растений. В 6 т. / гл. ред. А.Л. Тахтаждян. - Т. 5, ч. 2. - М.: Просвещение, 1981. - С. 169.

2. Черепанов С.К. Сосудистые растения СССР. - Л.: Наука, 1981. - 510 с.

3. Огольцова Т.П. Селекция черной смородины - прошлое, настоящее, будущее. Тула: Приок. кн. изд-во, 1992. - 384 с.

4. URL: http://www.apte.ru/product/Terra-plant_ ChERNAYa_SMORODINA.

5. Karjalainen R., Anttonen M., Saviranta N., Hilz H., Srewart D., Mcdougall G.J., Mattila P., Törrönene R. A Review on Bioactive Compounds in Black Currants (Ribes nigrum L.) and Their Potential Health-Promoting Properties // Acta Horticulturae. - 2009. - № 839. P. 301-307.

6. Салькова В.С., Санкин Л.С. Селекция отдаленных гибридов смородины черной на улучшение биохимического состава ягод в условиях Сибири // Современное садоводство. - 2010. - № 1. - С. 13-16.

7. Макаркина М.А., Янчук Т.В. Характеристики сортов смородины черной по содержанию сахаров и органических кислот // Современное садоводство. - 2010. - № 2. - С. 9-12.

8. Франчук Е.П. Биохимическая характеристика некоторых новых сортов черной смородины // Академия наук СССР. Биохимия плодов и овощей. - 1961. - Сб. 6. - С. 153 164.

9. Чепурко В.К. Изменение химического состава и товарных свойств ягод черной смородины под влиянием внекорневой подкормки микроэлементами: автореф. дис. ... канд. техн. наук: 05.18.15 / Моск. ин-т нар. хоз-ва. - М., 1971. - 26 с.

10. Макаркина М.А., Князев С.Д., Соколова С.Е., Филина Т.Г. Изучение биохимического состава ягод черной смородины с целью использования их в селекции // Состояние и перспективы селекции плодовых культур: мат-лы междунар. науч.-практ. конф., посвящ. 75-летию со дня родж. Г.К. Коваленко (21-24 авг. 2001 г., Самохваловичи). Минск, 2001. - С. 174-177.

11. Седова З.А., Леонченко В.Г., Астахов А.И. Оценка сортов по химическому составу плодов // Программа и методика сортоизучения плодовых, ягодных и орехоплодных культур / под общ. ред. Е.Н. Седова, Т.П. Огольцовой. - Орел: Изд-во ВНИИСПК, 1999. - С. 160-167.

12. Ренгартен Г.А., Сорокопудов В.Н. Оценка сортообразцов черемухи в зависимости от их генетического происхождения на северовостоке России // Вестн. КрасГАУ. - 2019. № 3 (144). - C. 51-57.

13. Куклина А.Г., Каштанова О.А., Сорокопудов В.Н. Фитосанитарный мониторинг жимолости синей в Средней России // Вестн. КрасГАУ. - 2019. - № 9. - С. 35-40.

14. Куклина А.Г., Сорокопудов В.Н., Гаврюшенко Е.В. Интродукционное испытание абрикоса в средней полосе России // Вестн. КрасГАУ. - 2019. - № 9. - С. 46-52.

\section{Literatura}

1. Cvelev N.N. Semejstvo Kryzhovnikovye (Grossulariaceae) // ZHizn' rastenij. V 6 t. I gl. red. A.L. Tahtazhdyan. - T. 5, ch. 2. - M.: Prosveshchenie, 1981. - S. 169.

2. Cherepanov S.K. Sosudistye rasteniya SSSR. L.: Nauka, 1981. - $510 \mathrm{~s}$.

3. Ogol'cova T.P. Selekciya chernoj smorodiny proshloe, nastoyashchee, budushchee. - Tula: Priok. kn. izd-vo, 1992. - 384 s.

4. URL: http://www.apte.ru/product/Terra-plant_ ChERNAYa_SMORODINA.

5. Karjalainen R., Anttonen M., Saviranta N., Hilz H., Srewart D., Mcdougall G.J., Mattila P., Törrönene R. A Review on Bioactive Compounds in Black Currants (Ribes nigrum L.) and Their Potential Health-Promoting Properties // Acta Horticulturae. - 2009. - № 839. P. 301-307.

6. Salykova V.S., Sankin L.S. Selekciya otdalennyh gibridov smorodiny chernoj na uluchshenie biohimicheskogo sostava yagod $v$ usloviyah Sibiri // Sovremennoe sadovodstvo. 2010. - № 1. - S. 13-16. 
7. Makarkina M.A., Yanchuk T.V. Harakteristiki sortov smorodiny chernoj po soderzhaniyu saharov i organicheskih kislot // Sovremennoe sadovodstvo. - 2010. - № 2. - S. 9-12.

8. Franchuk E.P. Biohimicheskaya harakteristika nekotoryh novyh sortov chernoj smorodiny /I Akademiya nauk SSSR. Biohimiya plodov i ovoshchej. - 1961. - Sb. 6. - S. 153-164.

9. Chepurko V.K. Izmenenie himicheskogo sostava i tovarnyh svojstv yagod chernoj smorodiny pod vliyaniem vnekornevoj podkormki mikroelementami: avtoref. dis. ... kand. tekhn. nauk: 05.18.15 / Mosk. in-t nar. hoz-va. - M., 1971. - $26 \mathrm{~s}$.

10. Makarkina M.A., Knyazev S.D., Sokolova S.E., Filina T.G. Izuchenie biohimicheskogo sostava yagod chernoj smorodiny $s$ cel'yu ispol'zovaniya in v selekcii // Sostoyanie i perspektivy selekcii plodovyh kul'tur: mat-ly mezhdunar. nauch.-prakt. konf., posvyashch. 75-letiyu so dnya rodzh. G.K. Kovalenko
(21-24 avg. 2001 g., Samohvalovichi). Minsk, 2001. - S. 174-177.

11. Sedova Z.A., Leonchenko V.G., Astahov A.I. Ocenka sortov po himicheskomu sostavu plodov /I Programma i metodika sortoizucheniya plodovyh, yagodnyh orekhoplodnyh kul'tur / pod obshch. red. E.N. Sedova, T.P. Ogol'covoj. - Orel: Izd-vo VNIISPK, 1999. - S. 160-167.

12. Rengarten G.A., Sorokopudov V.N. Ocenka sortoobrazcov cheremuhi $v$ zavisimosti ot in geneticheskogo proiskhozhdeniya na severovostoke Rossii // Vestn. KrasGAU. - 2019. № 3 (144). - S. 51-57.

13. Kuklina A.G., Kashtanova O.A., Sorokopudov V.N. Fitosanitarnyj monitoring zhimolosti sinej v Srednej Rossii // Vestn. KrasGAU. - 2019. № 9. - S. 35-40.

14. Kuklina A.G., Sorokopudov V.N., Gavryushenko E.V. Introdukcionnoe ispytanie abrikosa v srednej polose Rossii // Vestn. KrasGAU. - 2019. - № 9. - S. 46-52. 